\title{
Manganese Distribution between a Slag and a Bath of Molten Sponge Iron and Scrap
}

\author{
Mohammed MERAIKIB \\ Ministry of Energy and Industry, P.O. Box 2599, Doha, State of Oatar. \\ (Received on August 10, 1992; accepted in final form on October 16, 1992)
}

\begin{abstract}
Sponge iron and scrap were charged and melted in a 70 ton UHP electric arc furnace. Samples of molten metal and slag were taken and the data obtained from their analysis were used to investigate the effects of some process parameters on the thermodynamics and kinetics of manganese oxidation.

The present work shows that the activity coefficient of $(\mathrm{MnO})$ is mainly dependent on temperature and varies only slightly with the basicity. The partial molar enthalphy of solution of $\mathrm{MnO}$ in the slag is $45.3 \mathrm{~kJ} / \mathrm{mol}$. The activity of $(\mathrm{MnO})$ varies linearly with the concentration in the temperature range from 1550 to $1670^{\circ} \mathrm{C}$ and basicity range between 0.63 and 3.82 .

A linear relationship between the activity of $[\mathrm{Mn}]$ and the concentration upto about 1 wt $\%$ has been obtained, which shows that the average value of the activity coefficient is 0.9503 .

The manganate capacity and manganese distribution ratio are influenced mainly by the temperature and slightly by the basicity.

The rate controlling step in manganese oxidation is the transport of manganese to the slag-metal interface. The activation energy of manganese oxidation is $63.4 \mathrm{~kJ} / \mathrm{mol}$. The mass transfer coefficient and the diffusion coefficient of manganese are $0.0226 \mathrm{~cm} / \mathrm{s}$ and $7.0 \times 10^{-5} \mathrm{~cm}^{2} / \mathrm{s}$ respectively at $1600^{\circ} \mathrm{C}$.
\end{abstract}

KEY WORDS: steelmaking; electric arc furnace; sponge iron; manganese bahaviour.

\section{Introduction}

Sponge iron is consistently increasing in importance as a substitute for scrap in electric arc furnace steelmaking in such countries which have abundant and relatively inexpensive natural gas on the one hand and only limited supplies of local scrap on the other. The ratio of sponge iron to scrap in the metallic charge depends mainly on economic considerations.

The manganese content of sponge iron is usually low. Therefore, the main sources of manganese dissolved in a bath consisting of molten sponge iron and scarp are the scrap and the quantity of ferromanganese which may be fed to the furnace for deoxidation and adjusting the chemical composition of the metal before tapping.

In the present research, the effects of temperature and slag basicity on the activity coefficient of manganous oxide are investigated. Furthermore, the variation of the activity with the concentration of manganous oxide in the salg and the dependence of the activity on the content of manganese in the metal are examined. The effects of temperature, basicity and theoretical optical basicity of the slag on the manganate capacity are shown. The influences of temperature and slag basicity on the manganese distribution ratio are also considered. The kinetics of manganese oxidation are briefly treated.

\section{Experimental Procedure}

Charges consisting of sponge iron and scrap with the sponge iron proportions making up about 52, 70, 90 and $95 \%$ of the metallic charge (sponge iron and scrap) were melted in a 70 ton UHP electric arc furnace at Qatar Steel Company (QASCO). The sponge iron had, on average, a degree of metallization of $93.50( \pm 1.0$ ) and a carbon content of $1.50( \pm 0.1) \mathrm{wt} \%$.

The operation pattern of electric arc furnace using sponge iron and scrap is found in the literature. ${ }^{1,2)}$ The experimental procedure adopted in the present work is described in detail elsewhere. ${ }^{3)}$ An initial bucket charge weighing about 35 tons of scrap and sponge iron was fed into the furnace and power was switched on. As a molten pool had formed and a bath temperature of approximately $1570^{\circ} \mathrm{C}$ had been reached, the balance of the sponge iron and the required quantity of burnt lime were continuously charged into the furnace. As soon as the continuously charged sponge iron started to melt, the temperature was measured and the first slag sample and the corresponding metal sample were taken. Temperature measurement and sampling were repeated at different time intervals until metal tapping. The last pair of samples were collected from the ladle after final deoxidation with ferromanganese and ferrosilicon. 


\section{Results and Discussion}

The data obtained in this work are used to show the effects of slag composition and temperature on the activity coefficient and activity of manganous oxide in the slag as well as on the mangnate capacity and the partition ratio of manganese between slag and metal. Furthermore, the relationship between the activity and concentration of manganese in the bath is investigated and the kinetics of manganese oxidation are treated.

Average compositions of slag and metal samples collected at different stages of the steelmaking process with different proportions of sponge iron in the metallic charge are given in Table 1.

3.1. Activity Coefficient of Manganous Oxide in the Slag 3.1.1. Determination of the Activity Coefficient of Manganous Oxide

According to the theory of regular ionic solutions, the chemical potential of a component $i, \mu_{i}$, in a binary slag is

$$
\mu_{i}=\mu_{i}^{\circ}+R T \ln x_{i}+x_{j}^{2} Q_{i j},
$$

where $x_{i}$ and $x_{j}$ are the cation fractions of the two components $i$ and $j$ and $Q_{i j}$ is the energy of mixing of the two components.

The cation fraction, $x_{i}$, can be calculated from the slag analysis as follows

$$
x_{i}=\frac{n_{i}}{\sum v_{i} n_{i}},
$$

where $n_{i}$ is the number of moles of cation $i$ in $100 \mathrm{~g}$ of the slag and $v_{i}$ is the number of cations in a molecule of component $i$.

The activity of component $i, a_{i}$, can be expressed by the equation

$$
\mu_{i}=\mu_{i}^{\circ}+R T \ln a_{i}
$$

in which

$$
a_{i}=\gamma_{i} x_{i},
$$

where $\gamma_{i}$ is the activity coefficient of component $i$.

From Eqs. (1), (3) and (4), it follows that

$$
R T \ln \gamma_{i}=x_{j}^{2} Q_{i j}
$$

Basing on this equation, Kozheurov ${ }^{4,5)}$ had derived a general formula for the calculation of the activity coefficient of a component $l, \gamma_{l}$, in a multicomponent slag consisting of $k$ components as follows

$$
R T \ln \gamma_{l}=\sum_{i=1}^{l-1} x_{i} Q_{i l}+\sum_{i=l+1}^{k} x_{i} Q_{l i}-\sum_{i=1}^{k-1} \sum_{j=i+1}^{k} x_{i} x_{j} Q_{i j}
$$

Using this expression and the proper values of the heats of mixing of the components, Kozheurov obtained the following equations for the calculation of the activity coefficients of $(\mathrm{MnO})$ and $(\mathrm{FeO})$ in a slag consisting of $\mathrm{FeO}, \mathrm{MnO}, \mathrm{CaO}, \mathrm{MgO}, \mathrm{SiO}_{2}$ and $\mathrm{P}_{2} \mathrm{O}_{5}{ }^{4,5)}$

$$
\log \gamma_{(\mathrm{MnO})}=\log \gamma_{(\mathrm{FeO})}-\frac{2180}{T} x_{\mathrm{SiO}_{2}},
$$

where

$$
\begin{aligned}
& \log \gamma_{(\mathrm{FeO})}=\frac{1000}{T}\left[2.18 x_{\mathrm{MnO}_{\mathrm{SiO}_{2}}}\right. \\
& \left.\quad+5.90\left(x_{\mathrm{CaO}}+x_{\mathrm{MgO}}\right) x_{\mathrm{SiO}_{2}}+10.50 x_{\mathrm{CaO}} x_{\mathrm{P}_{2} \mathrm{O}_{5}}\right]
\end{aligned}
$$

The symbols are explained in the list of nomenclature.

$\gamma_{(\mathrm{MnO})}$ can also be easily calculated by combining the equilibrium constant and the equilibrium index of the reaction

\begin{tabular}{|c|c|c|c|c|c|c|c|c|c|c|c|c|c|c|c|}
\hline \multirow{2}{*}{$\begin{array}{l}\text { Average sponge } \\
\text { iron proportion } \\
\qquad(w t \%)\end{array}$} & \multirow{2}{*}{$\begin{array}{l}\text { Sample } \\
\text { No. }\end{array}$} & \multicolumn{9}{|c|}{ Average slag analysis (wt \%) } & \multicolumn{5}{|c|}{ Average metal analysis (wt \%) } \\
\hline & & $\mathrm{SiO}_{2}$ & $\mathrm{Al}_{2} \mathrm{O}_{3}$ & $\mathrm{CaO}$ & $\mathrm{MgO}$ & $\mathrm{MnO}$ & $\mathrm{FeO}$ & $\mathrm{Fe}_{2} \mathrm{O}_{3}$ & $\mathrm{P}_{2} \mathrm{O}_{5}$ & $s$ & $\mathrm{C}$ & $\mathrm{Si}$ & $\mathrm{Mn}$ & $\mathrm{P}$ & s \\
\hline \multirow[t]{4}{*}{52.7} & 1 & 20.52 & 5.35 & 35.01 & 18.68 & 5.36 & 9.84 & 2.93 & 0.22 & 0.09 & 0.55 & 0.05 & 0.51 & 0.02 & 0.03 \\
\hline & 2 & 19.44 & 5.09 & 34.50 & 21.34 & 4.21 & 9.45 & 4.15 & 0.25 & 0.04 & 0.25 & 0.02 & 0.22 & 0.01 & 0.02 \\
\hline & 3 & 19.01 & 4.91 & 31.23 & 23.97 & 6.04 & 8.65 & 3.91 & 0.21 & 0.04 & 0.24 & 0.01 & 0.63 & 0.02 & 0.02 \\
\hline & 4 & 33.73 & 6.60 & 20.74 & 28.50 & 4.07 & 2.90 & 1.29 & 0.06 & 0.02 & 0.34 & 0.21 & 1.35 & 0.02 & 0.02 \\
\hline \multirow[t]{4}{*}{69.8} & 1 & 18.46 & 5.00 & 46.29 & 12.98 & 2.57 & 7.94 & 5.01 & 0.29 & 0.09 & 0.28 & 0.08 & 0.31 & 0.02 & 0.01 \\
\hline & 2 & 18.64 & 5.32 & 41.96 & 17.30 & 2.52 & 7.00 & 4.84 & 0.32 & 0.05 & 0.25 & 0.05 & 0.19 & 0.01 & 0.01 \\
\hline & 3 & 18.40 & 5.23 & 38.62 & 17.73 & 5.05 & 7.50 & 5.02 & 0.28 & 0.04 & 0.29 & 0.03 & 0.56 & 0.02 & 0.01 \\
\hline & 4 & 22.51 & 5.57 & 34.15 & 22.01 & 7.10 & 4.16 & 2.27 & 0.07 & 0.05 & 0.36 & 0.20 & 1.27 & 0.02 & 0.01 \\
\hline \multirow[t]{4}{*}{95.3} & 1 & 18.14 & 4.51 & 44.02 & 13.00 & 1.35 & 8.71 & 7.95 & 0.26 & 0.01 & 0.23 & 0.03 & 0.11 & 0.01 & 0.004 \\
\hline & 2 & 18.60 & 4.72 & 42.80 & 14.78 & 1.63 & 6.93 & 8.67 & 0.23 & 0.01 & 0.22 & 0.04 & 0.13 & 0.01 & 0.003 \\
\hline & 3 & 18.81 & 5.80 & 39.85 & 16.47 & 4.11 & 5.93 & 6.92 & 0.19 & 0.01 & 0.25 & 0.01 & 0.57 & 0.01 & 0.004 \\
\hline & 4 & 22.55 & 6.98 & 33.77 & 21.39 & 6.44 & 4.52 & $1.9 \mathrm{I}$ & 0.10 & 0.01 & 0.36 & 0.14 & 1.17 & 0.02 & 0.004 \\
\hline
\end{tabular}

$$
[\mathrm{Mn}]+[\mathrm{O}]=(\mathrm{MnO}) \text {. }
$$

At low concentrations of manganese and oxygen in the metal, the equilibrium constant, $K$, can be expressed by

$$
K=\frac{a_{(\mathrm{MnO})}}{[\mathrm{Mn}][\mathrm{O}]}
$$

Table 1. Average slag and metal analyses for different sponge iron proportions in the metallic charge at different stages of steelmaking process.

1. Sample taken as soon as continuously charged sponge iron started to melt.

2. Sample taken just before adding ferromanganese to the furnace.

3. Sample taken at slagging-Off.

4. Sample taken from the ladle. 
The equilibrium index, $K^{\prime}$, on the other hand, is

$$
K^{\prime}=\frac{(\mathrm{MnO})}{[\mathrm{Mn}][\mathrm{O}]} \text {. }
$$

$K$ and $K^{\prime}$ are related to the temperature as follows ${ }^{6-8)}$

$$
\log K=\frac{12760}{T}-5.684
$$

and

$$
\log K^{\prime}=\frac{10024}{T}-2.334
$$

Division of Eq. (10) by Eq. (11) leads to

$$
\frac{K}{K^{\prime}}=\frac{a_{(\mathrm{MnO})}}{(\mathrm{MnO})}
$$

To estimate the activity of manganous oxide from Eq. (14), the value of the quotient $K / K^{\prime}$ at a given temperature can be calculated by using Eqs. (12) and (13); the concentration of the oxide is to be taken from the slag analysis. The activity coefficient, $\gamma_{(\mathrm{MnO})}$, can then be found from the relation

$$
\gamma_{(\mathrm{MnO})}=\frac{a_{(\mathrm{MnO})}}{N_{(\mathrm{MnO})}},
$$

where the mole fraction, $N_{(\mathrm{MnO})}$, is to be calculated from the chemical analysis of the slag.

The present investigation shows that the values of the activity coefficient determined from Eq. (15), $\gamma_{(\mathrm{MnO})_{(15)}}$, are similar to those calculated from Eq. (7), $\gamma_{(\mathrm{MnO})_{(7)}}$. Their relationship can be expressed by the regression equation

$$
\gamma_{(\mathrm{MnO})_{(15)}}=1.0210 \gamma_{(\mathrm{MnO})_{(7)}}, \quad r=0.6134, \sigma=0.0528 .
$$

Here, 83 values of $\gamma_{(\mathrm{MnO})_{(15)}}$ are correlated with the corresponding values of $\gamma_{(\mathrm{MnO})_{(7)}}$ in the temperature range $1560 \leq \vartheta \leq 1670^{\circ} \mathrm{C}$. The correlation coefficient, $r=0.6134$, is not high. This is because $\gamma_{(\mathrm{MnO})_{(15)}}$ takes relatively higher values than $\gamma_{(\mathrm{MnO})_{(7)}}$ as the temperature gets nearer to the lower limit of the temperature range under consideration. Completely different results are obtained when another temperature function of $K^{\prime 9)}$ is used which is supposed to be applicable to basic slags.

3.1.2. Effects of Temperature and Slag Basicity on the Activity Coefficient of Manganous Oxide

The variation of the activity coefficient of manganous oxide with the temperature and slag basicity was investigated by other authors. ${ }^{10-13)}$ Their results show that for a given slag composition, $\gamma_{(\mathrm{MnO})}$ decreases as the temperature is raised. At constant temperature, on the other hand, $\gamma_{(\mathrm{MnO})}$ increases as the basicity is increased. In other investigations, ${ }^{14}$ ) however, it was found that the activity coefficient of manganous oxide increases with the basicity at constant temperature and tends also to increase with the temperature at constant basicity. Data given in other publications ${ }^{15,16)}$ show that at constant temperature the value of $\gamma_{(\mathrm{MnO})}$ increases with the basicity and reaches a maximum value at a certain basicity.

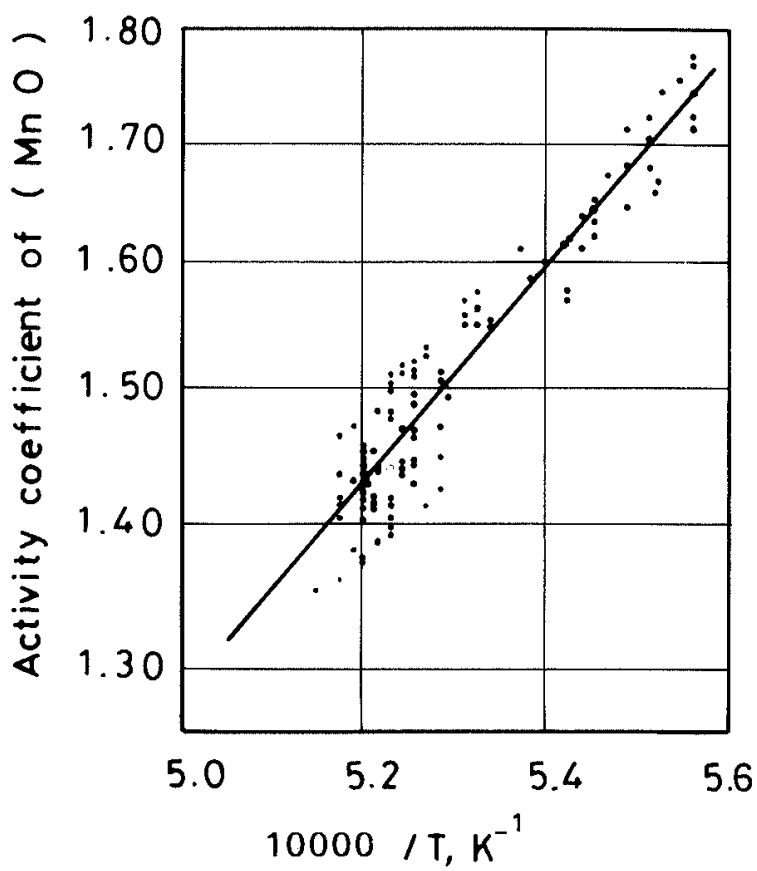

Fig. 1. Temperature dependence of the activity coefficient of manganous oxide, $\gamma_{(\mathrm{MnO})}$, in the slag.

In the present work, the activity coefficient of manganous oxide, calculated according to Eq. (15), is plotted against the reciprocal absolute temperature as shown in Fig. 1. The ranges of temperature, $\vartheta$, and basicity, $B$, are $1525 \leq \vartheta \leq 1670^{\circ} \mathrm{C}$ and $1.38 \leq B \leq 3.82$ respectively. The regression line obtained for 101 samples satisfies the equation

$\ln \gamma_{(\mathrm{MnO})}(T)=\frac{5450}{T}-2.4760, \quad r=0.9415, \sigma=0.1184$.

For a component $i$ in solution, the partial molar free energy of solution, $\Delta \bar{G}_{i}$, varies with the temperature as follows

$$
\frac{\partial\left(\Delta \bar{G}_{i} / T\right)}{\partial T}=-\frac{\Delta \bar{H}_{i}}{T^{2}},
$$

where $\Delta \bar{H}_{i}$ is the partial molar enthalpy of solution of the component $i$. On the other hand,

$$
\Delta \bar{G}_{i}=R T \ln a_{i} \text {. }
$$

From Eqs. (18) and (19), it follows that

$$
\frac{\partial\left(\ln a_{i}\right)}{\partial T}=-\frac{\Delta \bar{H}_{i}}{R T^{2}} .
$$

It is known that

$$
a_{i}=\gamma_{i} N_{i},
$$

where $a_{i}, \gamma_{i}, N_{i}$, are the activity, activity coefficient and mole fraction of the component $i$ in the solution. Since the mole fraction is independent of temperature, the variation of the activity coefficient with temperature can be expressed as

$$
\frac{\partial\left(\ln \gamma_{i}\right)}{\partial T}=-\frac{\Delta \bar{H}_{i}}{R T^{2}}
$$


Integration of this equation gives

$$
\ln \gamma_{i}=\frac{\Delta \bar{H}_{i}}{R T}+\text { constant }
$$

According to Eq. (23), a plot of $\ln \gamma_{i}$ versus $1 / T$ gives a straight line having a slope equal to $\Delta \bar{H}_{i} / R$. Comparing this with Eq. (17), it follows that the partial molar enthalpy of solution of $\mathrm{MnO}$ in the slag, under the conditions of the present investigations, is

$$
\Delta \bar{H}_{(\mathrm{MnO})}=45315 \mathrm{~J} / \mathrm{mol} \text {. }
$$

The average value of $\Delta \bar{H}_{(\mathrm{MnO})}$ in a given temperature range can be obtained by using the differential Eq. (22) and replacing the derivative by the ratio of finite increments, viz.,

$$
\left(\frac{d \ln \gamma_{(\mathrm{MnO})}}{d T}\right)_{a v}=\frac{\Delta \ln \gamma_{(\mathrm{MnO})}}{\Delta T}=-\frac{\Delta \bar{H}_{(\mathrm{MnO})}}{R\left(T_{a v}\right)^{2}} \ldots
$$

It follows, therefore, that

$$
\Delta \bar{H}_{(\mathrm{MnO})}=-R\left(T_{a v}\right)^{2}\left(\frac{\Delta \ln \gamma_{(\mathrm{MnO})}}{\Delta T}\right) .
$$

Using this equation in the temperature range $1525 \leq \vartheta \leq$ $1660^{\circ} \mathrm{C}$ and taking the corresponding values of $\ln \gamma_{(\mathrm{MnO})}$, it follows that the average value of $\Delta \bar{H}_{(\mathrm{MnO})}$ is $44880 \mathrm{~J} / \mathrm{mol}$. This value is in good agreement with that obtained from the slope of the straight line in Fig. 1, as given by Eq. (24). The positive sign of $\Delta \bar{H}_{(\mathrm{MnO})}$ indicates the endothermic nature of dissolution of $\mathrm{MnO}$ in the slag and the positive deviation from ideal behaviour.

Under the conditions of the present investigations, the effect of slag basicity, $B$, on the activity coefficient of manganous oxide at constant temperature seems to be very small, as shown in Fig. 2 . The points, however, show relatively big scatters around the regression lines. These lines may be represented by

$$
\ln \gamma_{(\mathrm{MnO})}(B, T)=0.020 B+b,
$$

where

$$
b=0.4635 \quad \text { at } 1550^{\circ} \mathrm{C} \text {, }
$$

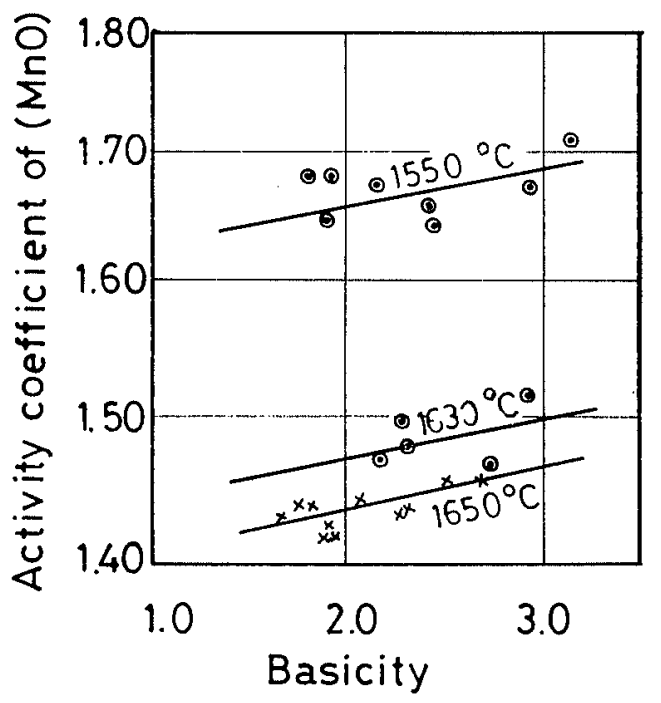

Fig. 2. Relationship between the activity coefficient of manganous oxide, $\gamma_{(\mathrm{MnO})}$, and the basicity of the slag.

$$
\begin{aligned}
& =0.3449 \text { at } 1630^{\circ} \mathrm{C}, \\
& =0.3212 \text { at } 1650^{\circ} \mathrm{C} .
\end{aligned}
$$

The respective correlation coefficients, $r$, have the values $0.650,0.420$ and 0.573 which reflect the big scatters and consequently the moderate to poor correlation of the data.

The values of $b$ are related to the temperature as follows

$$
b=\frac{5036}{T}-2.2984 \text {. }
$$

The combined effects of both basicity and temperature on $\gamma_{(\mathrm{MnO})}$, as follow from Eqs. (27) and (31), can be expressed by

$$
\gamma_{(\mathrm{MnO})}(B, T)=\exp \left(\frac{5036}{T}+0.020 B-2.2984\right) \text {. }
$$

At a temperature of $1630^{\circ} \mathrm{C}$, it follows from Eq. (17) that $\gamma_{(\mathrm{MnO})}(T)$ is 1.4739 . In this case the influence of the basicity of the slag on the activity coefficient of manganous oxide is not taken into consideration. For a slag at the same temperature and having a relatively high basicity of 3.0 , on the other hand, Eq. (32) leads to $\gamma_{(\mathrm{MnO})}(B, T)=1.5037$. This shows that the effect of the basicity on the activity coefficient of manganous oxide, under the conditions of the present work, is negligibly small, viz., $\left[\gamma_{(\mathrm{MnO})}(B, T)-\gamma_{(\mathrm{MnO})}(T)\right] 100 / \gamma_{(\mathrm{MnO})}(B, T)=$ $1.98 \%$.

\subsection{Activity of Manganous Oxide in the Slag}

The data obtained in the present investigations show that there is a linear relationship between the activity and the concentration of manganous oxide in the slag, as represented in Fig. 3. This can be expressed by

$a_{(\mathrm{MnO})}=1.2242 \times 10^{-2}(\mathrm{MnO}), \quad r=0.9969, \sigma=2.1519$.

Equation (33) is obtained for 100 samples collected in the temperature range $1550 \leq \vartheta \leq 1670^{\circ} \mathrm{C}$ and the basicity range $0.63 \leq B \leq 3.82$. The activity in the above

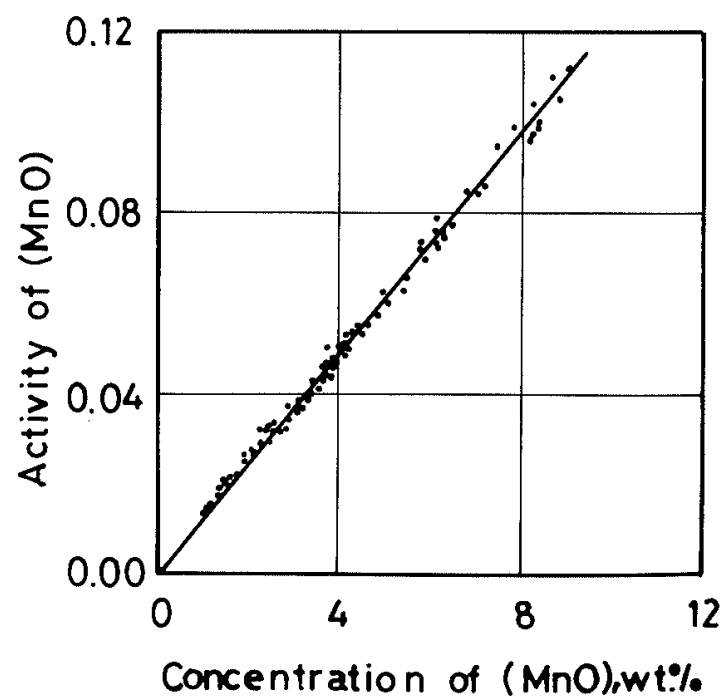

Fig. 3. Relationship between the activity and the concentration of manganous oxide in the slag. 
Table 2. Values of interaction parameters $e_{x}^{(i)} \cdot{ }^{17}$

\begin{tabular}{cccccccccccc}
\hline$e_{\mathrm{Mn}}^{(\mathrm{Mn})}$ & $e_{\mathrm{Mn}}^{(\mathrm{O})}$ & $e_{\mathrm{Mn}}^{(\mathrm{C})}$ & $e_{\mathrm{Mn}}^{(\mathrm{S})}$ & $e_{\mathrm{Mn}}^{(\mathrm{P})}$ & $e_{\mathrm{Mn}}^{(\mathrm{Si})}$ & $e_{\mathrm{O}}^{(\mathrm{O})}$ & $e_{\mathrm{O}}^{(\mathrm{C})}$ & $e_{\mathrm{O}}^{(\mathrm{S})}$ & $e_{\mathrm{O}}^{(\mathrm{Mn})}$ & $e_{\mathrm{O}}^{(\mathrm{P})}$ & $e_{\mathrm{O}}^{(\mathrm{Si})}$ \\
\hline 0 & -0.083 & -0.07 & -0.048 & -0.0035 & 0 & -0.20 & -0.45 & -0.133 & -0.021 & 0.070 & -0.131 \\
\hline
\end{tabular}

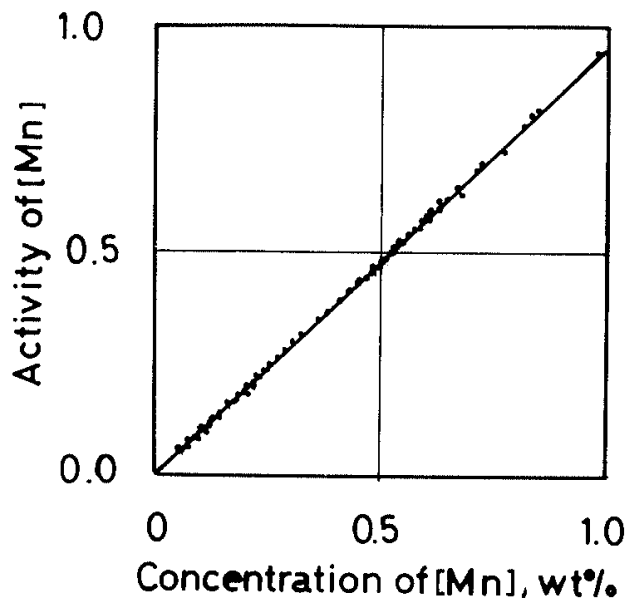

Fig. 4. Relationship between the activity and the concentration of manganese in the metal.

equation is calculated according to Eq. (14), using the values of $(\mathrm{MnO})$ obtained from the slag analysis.

Alternatively, $a_{(\mathrm{MnO})}$ can be calculated according to Eq. (4) by multiplying $\gamma_{(\mathrm{MnO})}$ found from Eq. (7) by the cation fraction of $(\mathrm{MnO}), x_{(\mathrm{MnO})}$, obtained from the slag analysis by using Eq. (2)

$$
a_{(\mathrm{MnO})}=\gamma_{(\mathrm{MnO})} x_{(\mathrm{MnO})} \text {. }
$$

In this case, the following relationship is obtained for the same samples

$a_{(\mathrm{MnO})}=1.1324 \times 10^{-2}(\mathrm{MnO}), \quad r=0.9959, \sigma=2.1519$.

It can be seen that Eqs. (33) and (35) are very similar.

\subsection{Activity of Manganese in the Bath}

The activity of manganese in the bath may be calculated according to

$$
a_{[\mathrm{Mn}]}=f_{[\mathrm{Mn}]}[\mathrm{Mn}] \text {, }
$$

where

$$
\begin{aligned}
\log f_{[\mathrm{Mn}]}= & e_{\mathrm{Mn}}^{(\mathrm{Mn})}[\mathrm{Mn}]+e_{\mathrm{Mn}}^{(\mathrm{O})}[\mathrm{O}]+e_{\mathrm{Mn}}^{(\mathrm{C})}[\mathrm{C}] \\
& +e_{\mathrm{Mn}}^{(\mathrm{S})}[\mathrm{S}]+e_{\mathrm{Mn}}^{(\mathrm{P})}[\mathrm{P}]+e_{\mathrm{Mn}}^{(\mathrm{Si})}[\mathrm{Si}] .
\end{aligned}
$$

The values of the interaction parameters, $e_{x}^{(i) 17)}$ are given in Table 2. The oxygen concentration in the metal, [O], can be calculated by using the activity of ferrous oxide in the slag which may be estimated according to the method of Kozheurov. ${ }^{3-5)}$

Figure 4 shows the dependence of the activity on the concentration of manganese for 87 metal samples taken in the temperature range $1550 \leq \vartheta \leq 1670^{\circ} \mathrm{C}$, and the concentration range $0.06 \leq[\mathrm{Mn}] \leq 1.0 \mathrm{wt} \%$. The regression line satisfies the equation

$$
a_{[\mathrm{Mn}]}=0.9503[\mathrm{Mn}], \quad r=0.9996, \sigma=0.2116 .
$$

By comparing Eqs. (36) and (38), the average value of

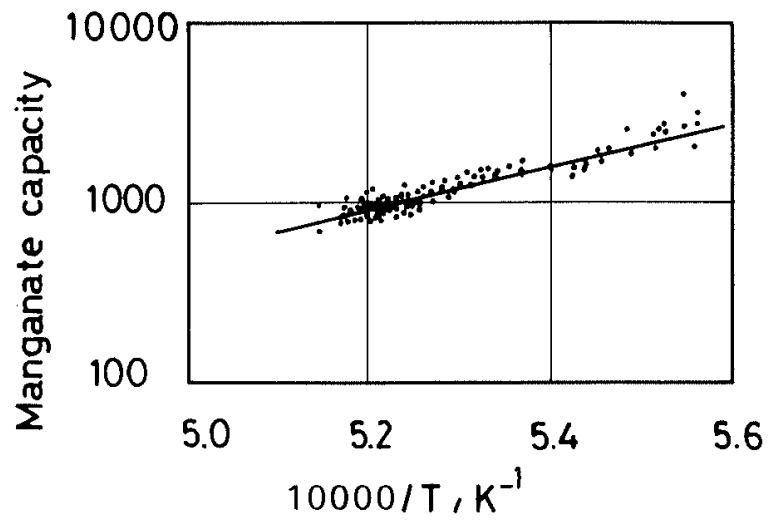

Fig. 5. Relationship between the manganate capacity and the temperature.

the activity coefficient of manganese in the bath is found to be $f_{[\mathrm{Mn}]}=0.9503$.

\subsection{Manganate Capacity}

The manganate capacity, $C_{\mathrm{Mn}}$, is defined as ${ }^{12)}$

$$
C_{\mathrm{Mn}}=\frac{(\mathrm{Mn})}{a_{[\mathrm{Mn}]} a_{[\mathrm{O}]}},
$$

where

$$
a_{[\mathrm{O}]}=f_{[\mathrm{O}]}[\mathrm{O}]
$$

and

$$
\begin{aligned}
\log f_{[\mathrm{O}]}= & e_{\mathrm{O}}^{(\mathrm{O})}[\mathrm{O}]+e_{\mathrm{O}}^{(\mathrm{C})}[\mathrm{C}]+e_{\mathrm{O}}^{(\mathrm{S})}[\mathrm{S}]+e_{\mathrm{O}}^{(\mathrm{Mn})}[\mathrm{Mn}] \\
& +e_{\mathrm{O}}^{(\mathrm{P})}[\mathrm{P}]+e_{\mathrm{O}}^{(\mathrm{Si})}[\mathrm{Si}] . \ldots \ldots \ldots \ldots \ldots \ldots \ldots \ldots
\end{aligned}
$$

Here, the oxygen concentration, [O], at a given temperature can be estimated by using Eqs. (10) and (12), whereby $a_{(\mathrm{MnO})}$ may be calculated according to Eq. (34). The values of [O] obtained in this way are used for calculating $a_{[\mathrm{O}]}$ required for estimating $C_{\mathrm{Mn}}$ in $\mathrm{Eq}$. (39). The concentration of manganese in the slag is found by multiplying $(\mathrm{MnO})$ by 0.7745 , whereas the activity of manganese in the metal is calculated from the metal analysis.

\subsubsection{Effects of Temperature and Slag Basicity on the Manganate Capacity}

The effect of temperature on the manganate capacity is shown for 114 values of $C_{\mathrm{Mn}}$ in Fig. 5. The corresponding samples were collected in the temperature range $1525 \leq \vartheta \leq 1670^{\circ} \mathrm{C}$ and the basicity range $0.63 \leq$ $B \leq 3.82$. The regression equation of the line is

$$
\ln C_{\mathrm{Mn}}(T)=\frac{27005}{T}-7.2324, \quad r=0.9373, \sigma=0.1186 \text {. }
$$

It seems that the effect of the slag basicity on the manganate capacity is small. This effect, however, can be found by plotting the manganate capacity against the 


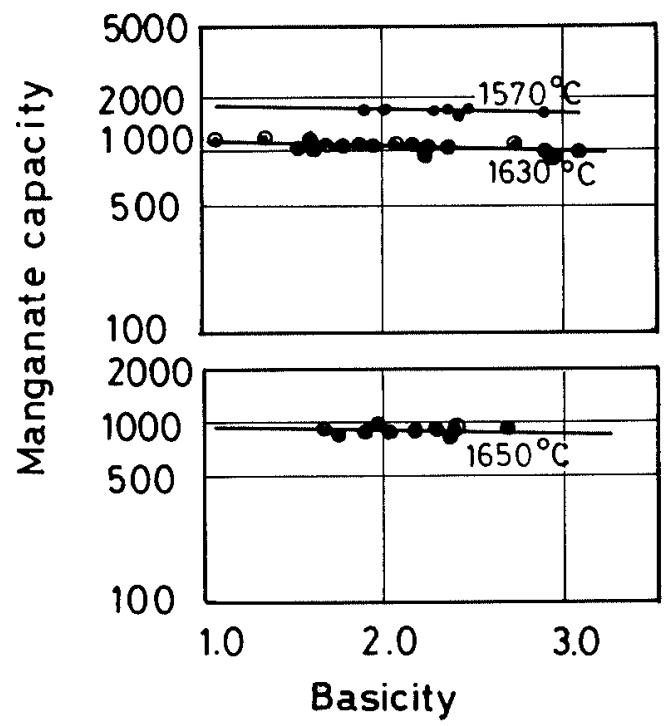

Fig. 6. Relationship between the manganate capacity and the basicity of the slag.

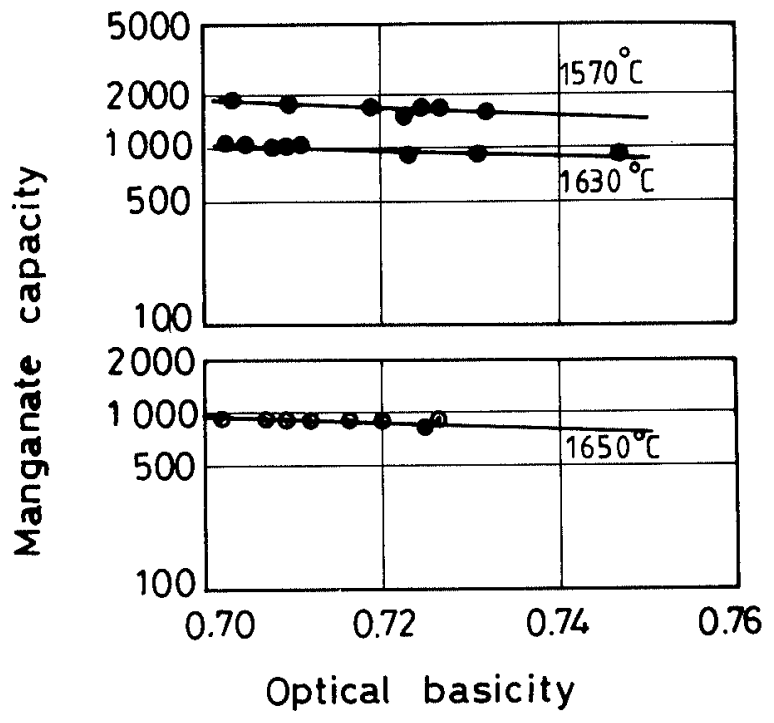

Fig. 7. Relationship between the manganate capacity and the optical basicity of the slag.

basicity, $B$, at constant temperature as shown in Fig. 6. The straight lines satisfy the regression equation

$$
\ln C_{\mathrm{Mn}}(B, T)=-0.0629 B+c,
$$

where -0.0629 is the average slope of the three lines, which are almost parallel, and

$$
\begin{aligned}
& c=7.5359 \text { at } 1570^{\circ} \mathrm{C} \text {, } \\
& =7.0871 \text { at } 1630^{\circ} \mathrm{C} \text {, } \\
& =6.9078 \text { at } 1650^{\circ} \mathrm{C} \text {. }
\end{aligned}
$$

In all cases, the value of the correlation coefficient is about -0.50 , indicating that the correlation is marginal.

The relationship between the above values of $c$ and the corresponding reciprocal absolute temperatures is

$$
c=\frac{27530}{T}-7.3952 \text {. }
$$

The effect of both basicity and temperature on the manganate capacity, as follows from Eqs. (43) and (47), is

$$
\ln C_{\mathrm{Mn}}(B, T)=\frac{27530}{T}-0.0629 B-7.3952 .
$$

As can be noted from this equation, the manganate capacity decreases with increasing temperature at constant basicity and tends also to decrease with increasing basicity at constant temperature.

Assuming a temperature of $1630^{\circ} \mathrm{C}$ and a slag basicity of 3.0, it follows from Eq. (42) that $C_{\mathrm{Mn}}(T)=1051.9$. If the effects of both basicity and temperature are taken into consideration, Eq. (48) leads to $C_{\mathrm{Mn}}(B, T)=975.3$. Therefore, the resulting decrease in the manganate capacity is $\left[C_{\mathrm{Mn}}(T)-C_{\mathrm{Mn}}(B, T)\right] 100 / C_{\mathrm{Mn}}(T)=7.3 \%$. This shows that, under the conditions of the present investigations, the slag basicity has only a limited effect on the manganate capacity.

\subsubsection{Effects of Temperature and Theoretical Optical Basicity on the Manganate Capacity}

Figure 7 shows the variation of the manganate capacity with the theoretical optical basicity of the slag, $\Lambda$, at constant temperature. The method of calculation of the optical basicity is given elsewhere. ${ }^{18,19)}$

The regression equation corresponding to the three lines in Fig. 7 can be expressed as follows

$$
\ln C_{\mathrm{Mn}}(\Lambda)=-4.2853 \Lambda+d
$$

In this equation

$$
\begin{aligned}
& -4.2853 \text { is the average value of } \\
& \text { the slopes of the three lines, } \\
& \begin{array}{l}
d=10.5346 \quad \text { at } 1570^{\circ} \mathrm{C}, \ldots \\
=9.9543 \quad \text { at } 1630^{\circ} \mathrm{C}, \ldots \\
=9.8822 \quad \text { at } 1650^{\circ} \mathrm{C}, \ldots
\end{array}
\end{aligned}
$$

The value of the correlation coefficient for the three lines is -0.64 , on average.

From Eqs. (50) to (52), the following formula can be obtained which shows the variation of $d$ with the temperature

$$
d=\frac{30100}{T}-5.8101
$$

The effect of both optical basicity and temperature on the manganate capacity, as follows from Eqs. (49) to (53), can be expressed by

$$
\ln C_{\mathrm{Mn}}(\Lambda, T)=\frac{30100}{T}-4.2853 \Lambda-5.8101 \text {. }
$$

It is again evident that the manganate capacity decreases with increasing temperature at constant optical basicity and also decreases with increasing optical basicity at constant temperature. Similar results were obtained by other authors. ${ }^{12)}$

\subsection{Manganese Distribution between Slag and Metal}

Equation (39) can be written in the form 


$$
C_{\mathrm{Mn}}=\eta_{\mathrm{Mn}} \frac{1}{f_{[\mathrm{Mn}]} a_{[\mathrm{O}]}}
$$

where

$$
\eta_{\mathrm{Mn}}=\frac{(\mathrm{Mn})}{[\mathrm{Mn}]}
$$

3.5.1. Effects of Temperature and Slag Basicity on the Manganese Distribution Ratio

The influence of temperature on the manganese distribution between the slag and the bath follows from Eqs. (42), (55) and (56), such that

$$
\eta_{\mathrm{Mn}}(T)=a_{[0]} f_{[\mathrm{Mn}]} \exp \left(\frac{27005}{T}-7.2324\right) \text {. }
$$

On the other hand, the combined effects of temperature and basicity on the manganese distribution can be obtained from Eqs. (48) and (55) as follows

$$
\eta_{\mathrm{Mn}}(B, T)=a_{[0]} f_{[\mathrm{Mn}]} \exp \left(\frac{27530}{T}-0.0629 B-7.3952\right) \text {. }
$$

The values of the manganese distribution ratio calculated from Eqs. (57) and (58), $\eta_{\mathrm{Mn} \text {, calc, }}$, are correlated here with the plant data, $\eta_{\text {Mn, obs }}$, for 80 metal samples and the corresponding slags collected in the temperature range $1550 \leq \vartheta \leq 1670^{\circ} \mathrm{C}$ and the basicity range $0.63 \leq B \leq 3.82$. In case of using Eq. (57), then

$$
\begin{aligned}
\eta_{\mathrm{Mn}, \mathrm{calc}}(T) & =1.0415 \eta_{\mathrm{Mn}, \mathrm{obs}}-0.1025, \\
r & =0.9894, \sigma=3.7774 \ldots \ldots
\end{aligned}
$$

If, on the other hand, Eq. (58) is used, the following expression will be obtained

$$
\begin{aligned}
\eta_{\mathrm{Mn}, \mathrm{calc}}(B, T) & =1.0125 \eta_{\mathrm{Mn}, \mathrm{obs}}-0.0380, \\
r & =0.9898, \sigma=3.7774 .
\end{aligned}
$$

This equation describes the straight line shown in Fig. 8.

Taking, e.g., a temperature of $1630^{\circ} \mathrm{C}$ and a basicity equal to 3.0, it follows from Eqs. (57) and (58) that $\left[\eta_{\mathrm{Mn}}(T)-\eta_{\mathrm{Mn}}(B, T)\right] 100 / \eta_{\mathrm{Mn}}(T)=7.30 \%$. This shows the limited influence of the basicity on the manganese distribution ratio in the present investigations.

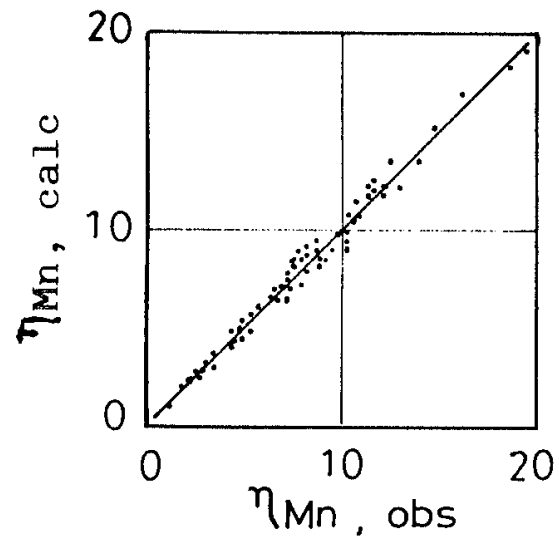

Fig. 8. Relationship between the distribution ratio of manganese calculated according to Eq. (58), $\eta_{\mathrm{Mn} \text {, calc }}$ and the corrsponding plant data, $\eta_{\mathrm{Mn}, \mathrm{obs}}$.

\subsection{Kinetics of Manganese Oxidation}

The oxidation of manganese may take place as a result of its reaction with the oxygen dissolved in the metal according to Eq. (9). Assuming that diffusion across the metal boundry layer is the rate limiting step in manganese oxidation, the overall reaction rate can be expressed as follows

$$
-\frac{d[\mathrm{Mn}]}{d t}=\beta_{\mathrm{Mn}} \alpha\left([\mathrm{Mn}]-[\mathrm{Mn}]^{*}\right)
$$

where

$$
\begin{gathered}
\beta_{\mathrm{Mn}}=\frac{D_{\mathrm{Mn}}}{\delta}, \\
\alpha=\frac{A}{V} .
\end{gathered}
$$

Integration of Eq. (61) leads to

$$
-\ln \left(\frac{[\mathrm{Mn}]_{t}-[\mathrm{Mn}]^{*}}{[\mathrm{Mn}]_{0}-[\mathrm{Mn}]^{*}}\right)=\beta_{\mathrm{Mn}} \alpha t
$$

where

$$
\begin{aligned}
& {[\mathrm{Mn}]=[\mathrm{Mn}]_{0} \quad \text { at } \quad t=0,} \\
& {[\mathrm{Mn}]=[\mathrm{Mn}]_{t} \quad \text { at } t=t .}
\end{aligned}
$$

At a given temperature, the value of $[\mathrm{Mn}]^{*}$ can be estimated from Eq. (10). In this case, $a_{(\mathrm{MnO})}$ is obtained from Eq. (14) as described before, and the oxygen concentration is determined by using the activity of ferrous oxide as explained elsewhere. ${ }^{3)}$ Equation (64) is then solved by plotting the left hand side versus time. If the assumptions made are valid, a straight line will be obtained having a slope equal to $\beta_{\mathbf{M n}} \alpha$. The results of applying this to the data obtained in the present investigations are shown in Fig. 9 for two initial concentrations of manganese in the metal: $[\mathrm{Mn}]_{0}=0.56$, $0.25 \mathrm{wt} \%$. The last metal sample and the corresponding slag sample were taken just before adding ferromanganese to the melt in the furnace. The scatter of the points obtained from the chemical analysis of the samples about the regression lines is acceptable for industrial heats. This indicates that the model suggested for manganese oxidation is applicable to the present investigations. The slopes of the two lines are $4.405 \times 10^{-4}$ and $2.090 \times 10^{-4}$

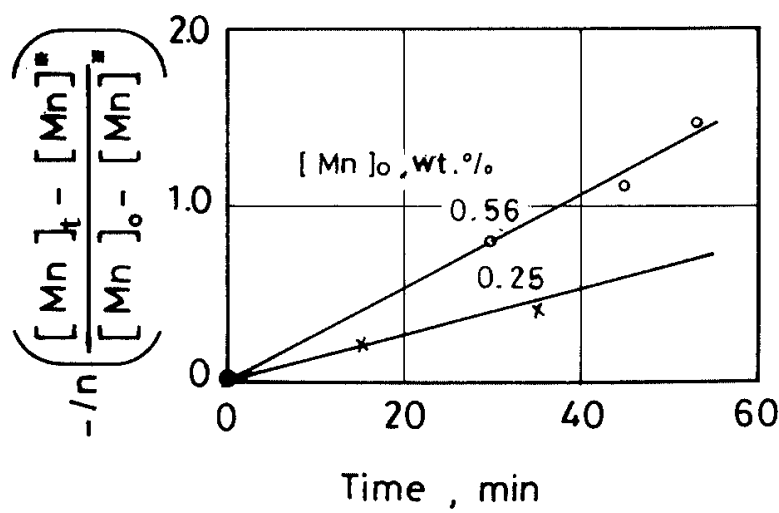

Fig. 9. Diagram for the determination of $\beta_{\mathrm{Mn}} \alpha$ according to Eq. (64) for two initial manganese concentrations $[\mathrm{Mn}]_{0}=0.56,0.25 \mathrm{wt} \%$. 


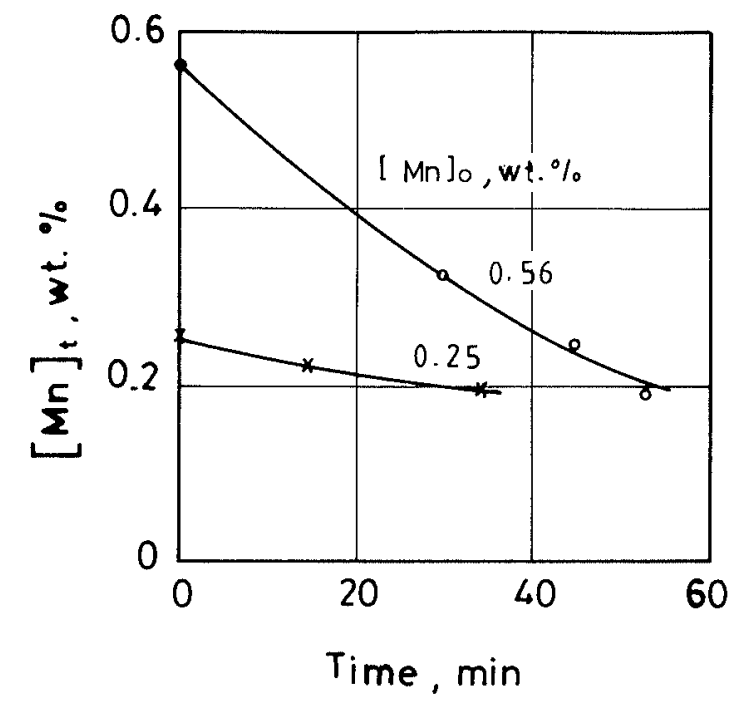

Fig. 10. Relationship between the concentration of manganese in the metal and the time for two initial manganese concentrations $[\mathrm{Mn}]_{0}=0.56,0.25 \mathrm{wt} \%$. Theoretical curves and experimental points.

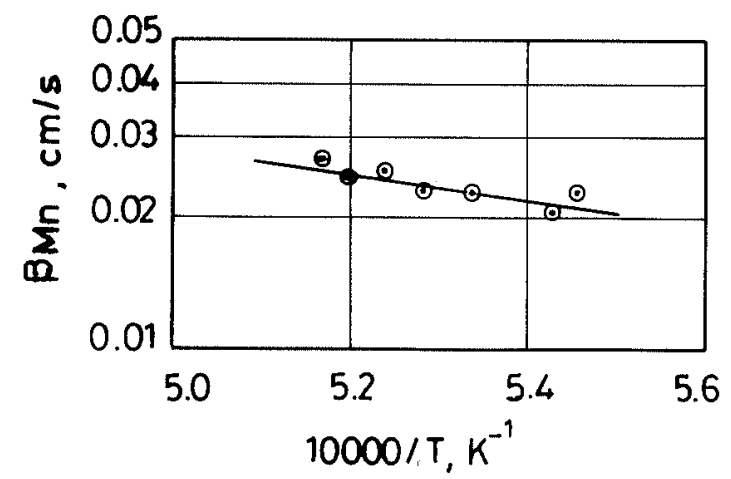

Fig. 11. Relationship between the mass transfer coefficient of manganese and the temperature for the determination of the "activation energy" of the manganese oxidation.

$\mathrm{s}^{-1}$, corresponding to $[\mathrm{Mn}]_{0}=0.56$ and $0.25 \mathrm{wt} \%$ respectively.

The calculation of manganese concentration in the bath at any time, $[\mathrm{Mn}]_{t}$, follows from Eq. (64) which may be written as

$$
[\mathrm{Mn}]_{t}=[\mathrm{Mn}]^{*}+\left([\mathrm{Mn}]_{0}-[\mathrm{Mn}]^{*}\right) \exp \left(-\beta_{\mathrm{Mn}} \alpha t\right) .
$$

Figure 10 shows the variation of the manganese content of the bath with the time for the two heats having $[\mathrm{Mn}]_{0}=0.56$ and $0.25 \mathrm{wt} \%$. The two curves are calculated by using Eq. (67) and the slopes of the two lines in Fig. 9. The good agreement between the practical data and the theoretical curves shows that the proposed kinetic model is applicable to the oxidation of manganese dissolved in the bath, under the conditions of these investigations.

To estimate the "activation energy" of the manganese oxidation reaction, the logarithm of the mass transfer coefficient, $\beta_{\mathrm{Mn}}$, is plotted against the reciprocal absolute temperature, as shown in Fig. 11. The values of the mass transfer coefficient at different temperatures are found by using Eq. (64) and dividing the value of the left hand side of this equation corresponding to a given temperature by $\alpha t$. In this investigation, $\alpha$ represents the cross-sectional area of the furnace at the slag-metal interface per unit volume of the metal and has an average value equal to $0.018 \mathrm{~cm}^{-1}{ }^{3)}$ The following expression gives the relationship between the mass transfer coefficient and the temperature as represented in Fig. 11

$$
\beta_{\mathrm{Mn}}=1.33 \exp (-63400 / R T) .
$$

According to this equation, the activation energy of manganese oxidation is $63.4 \mathrm{~kJ} / \mathrm{mol}$. This value lies within the range of the activation energies given for diffusion in liquid metals ${ }^{20)}$ and is of the same order as that reported for the diffusion of manganese in liquid iron. ${ }^{21)}$

These observations indicate that the transport of manganese in the metal to the slag-metal interface is the rate limiting step in manganese oxidation.

At $1600^{\circ} \mathrm{C}$, the mass transfer coefficient calculated according to Eq. (68) is $\beta_{\mathrm{Mn}}=0.0226 \mathrm{~cm} / \mathrm{s}$. It was found in earlier investigations, ${ }^{3)}$ carried out under the same conditions as the present work, that the thickness of the boundary layer is $\delta=3 \cdot 1 \cdot 10^{-3} \mathrm{~cm}$. Substituting this value in Eq. (62), it follows that the diffusion coefficient of manganese in liquid steel is $D_{\mathrm{Mn}}=7.0 \cdot 10^{-5} \mathrm{~cm}^{2} / \mathrm{s}$.

This value is within the range given in the literature for the diffusion coefficient of manganese in liquid steel under normal steelmaking process conditions. ${ }^{22)}$

\section{Conclusions}

Charges consisting of sponge iron and scrap, with the sponge iron proportion varying from about 52 to $95 \%$, were melted in a 70 ton UHP electric arc furnace. The data obtained from the analyses of metal samples and the corresponding slags collected at different temperatures and various time intervals are used to investigate the influences of some important process parameters on the thermodynamics and kinetics of manganese oxidation. The following results were obtained:

(1) The activity coefficient of manganous oxide in the slag depends mainly on the temperature. Its variation with the basicity, on the other hand, is limited. The partial molar enthalpy of solution of manganous oxide in the slag is $45.3 \mathrm{~kJ} / \mathrm{mol}$.

(2) The activity of manganous oxide in the slag varies linearly with the concentration in the investigated temperature range between 1550 and $1670^{\circ} \mathrm{C}$ and basicity range from 0.63 to 3.82 .

(3) The activity of manganese dissolved in the bath also varies linearly with the concentration (up to about $1 \mathrm{wt} \%$ ) and the activity coefficient of manganese is 0.9503 .

(4) The manganate capacity is affected mainly by the temperature. Its dependence on the basicity and optical basicity of the slag, however, is small.

(5) The effects of temperature and basicity on the manganese distribution ratio are similar to their effects on the manganate capacity.

(6) The oxidation of manganese is controlled by the transport of manganese to the slag-metal interface. The 
activation energy of manganese oxidation is $63.4 \mathrm{~kJ} / \mathrm{mol}$. At $1600^{\circ} \mathrm{C}$, the mass transfer coefficient and the diffusion coefficient of manganese are $0.0226 \mathrm{~cm} / \mathrm{s}$ and $7.0 \times 10^{-5}$ $\mathrm{cm}^{2} / \mathrm{s}$, respectively.

\section{Acknowledgement}

The author is indebted to Qatar Steel Co., Ltd. for conducting the tests.

\section{Nomenclature}

$A$ : area of reaction interface $\left(\mathrm{cm}^{2}\right)$

$a_{i}$ : activity of substance $i$ in solution

$a_{(x)}, a_{[x]}$ : activity of species $x$ in slag and metal respectively

$B$ : basicity of slag, $B=(\mathrm{CaO}) /\left(\mathrm{SiO}_{2}\right)$

$b$ : intercept of straight line according to Eqs. (27) to (31)

$C_{\mathrm{Mn}}$ : Manganate capacity according to Eq. (39)

$c$ : intercept of straight line according to Eqs. (43) to (47)

$D_{\mathrm{Mn}}$ : diffusion coefficient of manganese in molten metal $\left(\mathrm{cm}^{2} / \mathrm{s}\right)$

$d$ : intercept of straight line according to Eqs. (49) to (53)

$e_{x}^{(i)}$ interaction parameter

$f_{[x]}:$ activity coefficient of species $x$ in molten metal

$K$ : equilibrium constant according to Eq. (10)

$K^{\prime}$ : equilibrium index according to Eq. (11)

$[\mathrm{Mn}],[\mathrm{Mn}]_{0},[\mathrm{Mn}]_{t},[\mathrm{Mn}]^{*}:$ concentration, initial concentration, concentration at time $t$, equilibrium concentration of manganese in molten metal (wt\%)

$N_{i}$ : mole fraction of substance $i$ in solution

$n_{i}$ : number of moles of cation $i$ in $100 \mathrm{~g}$ of slag

$N_{\text {(MnO) }}$ : mole fraction of manganous oxide in slag

$Q_{i j}$ : energy of mixing of components $i, j$

$R$ : gas constant $(\mathrm{J} / \mathrm{K} \mathrm{mol})$

$r$ : correlation coefficient

$T$ : absolute temperature (K)

$T_{a v}$ : average temperature (K)

$t:$ time (s)

$V:$ volume of molten metal $\left(\mathrm{cm}^{3}\right)$

$(x),[x]$ : concentration of species $x$ in slag and metal respectively (wt \%)

$x_{i}, x_{j}$ : cation fractions of components $i, j$

$x_{(\mathrm{MnO})}$ : cation fraction of $\mathrm{MnO}$ in the slag

$\alpha$ : area of reaction interface per unit volume of molten metal according to Eq. (63) $\left(\mathrm{cm}^{-1}\right)$

$\beta_{\mathrm{Mn}}$ : mass transfer coefficient of manganese according to Eq. (62) $(\mathrm{cm} / \mathrm{s})$

$\gamma_{i}$ : activity coefficient of substance $i$ in solution

$\gamma_{(\mathrm{MnO})}$ : activity coefficient of manganous oxide in slag

$\Delta \bar{G}_{i}$ : partial molar free energy of solution of substance $i(\mathrm{~J} / \mathrm{mol})$

$\Delta \bar{H}_{i}$ : partial molar enthalpy of solution of substance $i(\mathrm{~J} / \mathrm{mol})$

$\Delta \bar{H}_{(\mathrm{MnO})}$ : partial molar enthalpy of solution of manganous oxide in slag $(\mathrm{J} / \mathrm{mol})$

$\delta$ : thickness of diffusion boundary layer according to Eq. (62) (cm)

Ұ: temperature $\left({ }^{\circ} \mathrm{C}\right)$

$\Lambda$ : theoretical optical basicity

$\mu_{i}^{\circ}, \mu_{i}$ : chemical potentials of component $i$ in the standard state and in solution

$v_{i}$ : number of cations in a molecule of component $i$

$\sigma:$ standard deviation

\section{REFERENCES}

1) S. Mitsushima: Trans. Iron Steel Inst. Jpn., 20 (1980), 318.

2) E. Maarouf, M. Kano, R. M. Al-Kowari and K. A. Afzal: 1st European Electric Steel Cong., Aachen, Federal Republic of Germany, September 12 to 14, (1983), ed. by Verein Deutscher Eisenhüttenleute, Verlag Stahleisen mbH, Düsseldorf, (1983), B3.

3) M. Meraikib: Steel Res., 57 (1986), 626.

4) V. Grigorian, L. Belyanchikov and A. Stomakhin: Theoretical Principles of Electric Steelmaking, Mir Publishers, Moscow, (1983), 73.

5) S. Filippov: The Theory of Metallurgical Processes, Mir Publishers, Moscow, (1975), 227.

6) R. Zimmermann and K. Günther: Metallurgie und Werkstofftechnik, Vol. 2, VEB Deutscher Verlag für Grundstoffindustrie, Leipzig, (1975), 48.

7) F. Oeters: Die physikalische Chemie der Eisen- und Stahlerzeugung, ed. by Verein Deutscher Eisenhüttenleute, Verlag Stahleisen mbH, Düsseldorf, (1964), 171.

8) B. A. Burdonov and P. I. Yugov: Steel USSR, 15 (1985), 472.

9) H. Burghardt and G. Neuhof: Stahlerzeugung, VEB Deutscher Verlag für Grundstoffindustrie, Leipzig, (1982), 76.

10) C. Bodsworth: Physical Chemistry of Iron and Steel Manufacture, Longmans, London, (1963), 163; 340.

11) McGannon (Editor), The Making, Shaping and Treating of Steel, 9th Edition, United States Steel, Pittsburg, (1971), 376.

12) R. Inoue and H. Suito: Trans. Iron Steel Inst. Jpn., 24 (1984), 816.

13) S. R. Simeonov and N. Sano: Trans. Iron Steel Inst. Jpn., 25 (1985), 1116.

14) H. Suito and R. Inoue: Trans. Iron Steel Inst. Jpn., 24 (1984), 257.

15) H. L. Bishop Jr., N. J. Grant and J. Chipman: Trans. AIME, 212 (1958), 890; H. Suito and R. Inoue: Trans. Iron Steel Inst. Jpn., 24 (1984), 260.

16) J.F. Elliott and F. W. Luerssen: Open Hearth Proceedings AIME, 37 (1954), 193; Trans. AIME, 203 (1955), 1129; H. Suito and R. Inoue: Trans. Iron Steel Inst. Jpn., 24 (1984), 260.

17) V. Grigorian, L. Belyanchikov and A. Stomakhin: Theoretical Principles of Electric Steelmaking, Mir Publishers, Moscow, (1983), 54.

18) D. R. Gaskell: Trans. Iron Steel Inst. Jpn., 22 (1982), 997.

19) M. Meraikib: Steel Res., 59 (1988), 449.

20) J. Szekely and N. J. Themelis: Rate Phenomena in Process Metallurgy, John Wiley \& Sons Inc., New York, London, Sydney, Toronto, (1971), 370.

21) V. Grigorian, L. Belyanchikov and A. Stomakhin: Theoretical Principles of Electric Steelmaking, Mir Publishers, Moscow, (1983), 167.

22) V. I. Baptizmanskii and Yu. S. Paniotov: Steel USSR, 3 (1973), 471 . 